\title{
Probiotics in the treatment of gastrointestinal diseases
}

\author{
FILIP PRZERWA ${ }^{1 \oplus}$, ARNOLD KUKOWKA $^{2} \oplus$, KATARZYNA KOTRYCH $^{3 \oplus}$, IZABELA UZAR $^{4 \oplus}$
}

\author{
${ }^{1,2}$ Student Science Club \\ Department of General Pharmacology and Pharmacoeconomics \\ Pomeranian Medical University \\ Szczecin, Poland \\ ${ }^{3}$ Department of General and Dental Radiology \\ Pomeranian Medical University \\ Szczecin, Poland \\ ${ }^{4}$ Department of General Pharmacology and Pharmacoeconomics \\ Pomeranian Medical University \\ Szczecin, Poland \\ *corresponding author: e-mail: uzari@wp.pl
}

\section{Summary}

The human microbiota has a tremendous effect on our health. In the last decades, our knowledge about interactions between bacteria and humans have grown greatly. Not only is it necessary for humans to synthesize vitamins, to have tight intestinal barriers or protect from pathogens, it also has an impact on our immune system and thus plays an important role in autoimmune diseases and prevention of excessive inflammatory response. The idea of probiotics is to restore the balance in humans digestive microbiota. There is a growing number of scientific papers that proves a positive impact of using probiotics in various diseases. However, there are still questions that need to be answered before probiotics play a bigger role in the treatment. This paper presents the information about the use of probiotics in most common diseases of gastrointestinal tract.

Key words: probiotics, gastrointestinal diseases, microbiota

Słowa kluczowe: probiotyki, choroby układu pokarmowego, mikrobiota 


\section{INTRODUCTION}

The development of medicine in the XXI century is becoming faster and more dynamic. New causes and pathomechanisms of diseases, which were previously shrouded in secrecy, are regularly discovered. Doctors and scientists all over the world are constantly working on solving new puzzles posed by our own body. New therapies and drugs make it possible to treat diseases that previously seemed incurable. The more our knowledge of the human body deepens, the more the complexity and variety of processes that occur within it come to the fore.

One of the most groundbreaking discoveries in human history was the discovery of bacteria by Antoni van Leeuwenhoek in 1674. As time passed, it was understood that a parallel micro-world within the human body may be crucial for its proper functioning and even existence. Bacteria inhabit our skin, respiratory tract, genitourinary system and, above all, gastrointestinal tract, and are an essential element in maintaining homeostasis of the entire body.

The microorganisms that inhabit a given environment are defined as the microbiota. In the case of the digestive microbiota, these include bacteria, archaeons [1], fungi [2] and viruses [3]. The microbiota of digestive system has evolved. It interacts with the human body to provide many benefits [4]

The role of bacteria in the pathomechanism of various diseases is increasingly taken into account. The development of knowledge about human microbiota brings hope for understanding the ways of their modulations. One of currently available methods influencing human microbiota is use of probiotics. These are defined as live microorganisms that, when administered in adequate amounts, have a beneficial effect on the health of the recipient [5]. A possible modulator of intestinal microbiota are also prebiotics. Prebiotic is a substance present or introduced into the food in order to stimulate the development of normal intestinal flora. In contrast to a probiotic, it contains no microorganisms, only their stimulants. These substances can be proteins, fats, oligo- or polysaccharides that are not digested and reach the intestinal lumen in an unchanged form to develop their effects in this place. There are many prebiotics occuring spontaneously in nature: for example in leeks, chicory, garlic, onions, asparagus or Jerusalem artichokes. Addition of prebiotics to different types of foods can potentially protect and repair the microbiome composition, especially in Western countries in which the diet contains low amounts of those prebiotics. Polysaccharides that can be extracted from agave and chicory crops - inulin, can be used to produce oligofructose (through hydrolysis). Sucrose and lactose can be used, in enzymatic reactions, to obtain short-chain fructooligosaccharides (scFOS) or trans-galactooligosaccharides (TOS) [6]. Synbiotics contain in their composition a probiotic and a prebiotic [6].

In this paper the use of probiotics in gastrointestinal diseases such as irritable bowel syndrome, inflammatory bowel disease, peptic ulcer disease, peristalsis disorders, gastroesophageal reflux, lactose intolerance and liver diseases will be presented.

\section{GUT MICROBIOTA}

\section{Physiology and modulation of gut microbiota}

The gut microbiota is an important and integral part of our bodies. It develops since birth, when maternal microbiota colonizes the newborn [7]. At this stage, early immune response formulates in intestinal mucosa. The interaction between microbiota and epithelial cells leads to the activation of inflammatory pathways as well as subsequent desensitization. Both processes are extremely important because they result in the formation of a protective mucin and immune response system against harmful microorganisms [8]. The quantitative and qualitative composition of microbiota undergoes numerous changes in life course. Bacterial colonies also vary, depending on the location in the gastrointestinal tract they inhabit. Intestinal bacteria form a specific, dynamic system that intervenes in a number of processes in human body, e.g. in immune system or in metabolic pathways [9].

In average adult human, the sum of microorganisms found in the gastrointestinal tract far exceeds their number in other structures of the body. It is estimated that there are about 100 trillion of them, or about ten times more than all the cells in the human body [10]. The digestive system is colonized by over a thousand different species of prokaryotes. The seven main types of bacteria are: Bacteroidetes, Actinobacteria, Firmicutes, Fusobacteria, Proteobacteria, Verrucomicrobia and Cyanobacteria. In 90\% the flora consists of Bacteroidetes and Firmicutes [11].

The relationship between human organism and internal bacteria is traditionally referred to as commensalism. This is a type of protective interaction between organisms in which one species clearly benefits without harming the other one. However, the number of interactions and their level of complexity is huge. That is why relating them to commensalism is definitely downplaying the enormity 
of the functions and mechanisms of microorganisms [12]. Given the importance of the influence of microbiota on the human body, serious consideration should be given to the means of its modulation and the opportunities associated with it - both in improving health and in the treatment of serious diseases. Disturbances of the intestinal microbiota are studied for their role in a number of pathological processes leading to the development of diseases such as atherosclerosis, autoimmune diseases, or diseases affecting the gastrointestinal tract. The way to modulate the composition of bacterial intestinal microbiota is the use of probiotics, prebiotics, and their combination - synbiotics. There is an ample clinical evidence of the positive effects of the use of such supplementation in the treatment of many diseases. It can be expected that with the development of science and increase of research in this direction, even more applications of microbiota modulation will be discovered [13].

Probiotic bacteria can be supplied in dairy products such as kefir or yogurt or in preparations such as tablets, capsules or powders. The natural form of dairy products unfortunately poses some problems - a short expiration date and frequent lack of information from the manufacturer on the total number of bacterial colonies (CFU - colony forming units) and uncertainty about the actual composition and viability of bacterial cultures. Additional limitations result from the influence of other ingredients contained in these products, such as fats, lactose and casein. It has also been proven that excessive consumption of dairy products can lead to an increased risk of inflammatory bowel diseases [14]. When probiotics are administered in the form of supplements, consideration should be given to the characteristics that a good probiotic should have. The basic and most important assumption is their safety and the lowest number of potential side effects. A key requirement is also that they can reach and populate the gastrointestinal tract. Therefore, the preparation should be resistant to hydrochloric acid and bile, allowing the passage of colonies into the intestines. Bacteria should also have the ability to adhere to the intestinal epithelium in order to synthesize antimicrobial compounds. Good quality probiotics of are derived from human material, which increases their bioavailability. Unfortunately, many supplements containing probiotic bacteria, available in pharmacies, have in general poorly documented effects on human body and poor efficacy, which questions the purpose and safety of their use. It is therefore necessary to continue the search for appropriate types, species and strains of bacteria that can help fight various diseases.

There are three main mechanisms of action for probiotic bacteria (tab. 1). The first is competition with other bacteria for nutrients and an optimal environment. This weakens the growth of colonies of potentially dangerous bacteria, limiting the development of their pathogenic potential [15].

Probiotics can also have a direct effect on other microorganisms - preventing pathogen adhesion and subsequent colonization of the gastrointestinal tract [16]. Another mechanism is the production of substances against pathogens such as bacteriocins, organic acids, and short chain fatty acids $[17,18]$. They limit the growth of potentially harmful bacteria in the gastrointestinal tract, but also by creating a hostile environment leading to their death and inactivation of toxins produced by pathogens. The third function of probiotics is the stimulation and modulation of the immune system, both specific and non-specific responses. This occurs through activation of T lymphocytes, production of cytokines, induction of phagocytosis, and stimulation of IgA antibody secretion [19, 20]. Through interaction with many cells of immune system, probiotics stimulate the body to synthesize defensins, antimicrobial proteins, and lecithin. This has a positive effect on the body by altering the overall profile of pro- and anti-inflammatory cytokines and facilitating the inactivation of potentially harmful microorganisms, but also the toxins produced by them $[21,22]$. Modulating the composition of gut microbiota with probiotics can lead to lower levels of inflammatory markers, enhanced protection against oxidative stress, and reduced duration, frequency, and severity of digestive symptoms.

Table 1.

Main functions of the gut microbiota

\begin{tabular}{|c|c|c|}
\hline Protective & Metabolic & Structural \\
\hline $\begin{array}{l}\text { - Strengthening the intestinal barrier } \\
\text { - Prevention of pathogen multiplication } \\
\text { - Secretion of antimicrobial compounds } \\
\text { - Participation in immune processes }\end{array}$ & $\begin{array}{l}\text { - Synthesis of amino acids and vitamins } \\
\text { - Biotransformation of bile acids } \\
\text { - Production of short-chain fatty acids } \\
\text { - Fermentation of fibre }\end{array}$ & $\begin{array}{l}\text { - "Tight-junctions" regulation } \\
\text { - Development of villi and intestinal } \\
\text { crypts } \\
\text { - Effect on the mucous membrane of the } \\
\text { gastrointestinal tract }\end{array}$ \\
\hline
\end{tabular}




\section{Microbiota and digestive diseases}

Among contemporary hypotheses regarding functional disorders of the gastrointestinal tract, the effect of altering the microbiota of the small intestine is considered [23]. Dysbiosis is the abnormal composition of the microbiota - impaired permeability of the intestinal barrier and activation of inflammation [24]. Dysbiosis plays a role in, among others, irritable bowel syndrome [25] and inflammatory bowel disease [26].

Other factors that can disrupt gastrointestinal homeostasis are numerous environmental factors such as diet, chronic stress, stimulants, or medications, e.g. NSAIDs, PPIs [27]. Restoration of natural gut microbiota can help improve the patients' quality of life. Probiotic supplementation may improve prognosis in gastrointestinal diseases and disorders. It seems that probiotics play a large role in gastrointestinal diseases, as it was indicated in numerous studies.

\section{USE OF PROBIOTICS IN GASTRO- INTESTINAL DISEASES}

\section{Irritable bowel syndrome}

Some bacterial strains are recommended for the treatment of irritable bowel syndrome (IBS): - Bifidobacterium infantis 35624; Bifidobacterium animalis ssp.lactis DN-173010, Lactobacillus casei Shirota; Lactobacillus plantarum 299v, Lactobacillus rhamnosus GG, Escherichia coli Nissle 1917. Also multispecies probiotics, without specifying particular strains, are recommended in patients with IBS. According to both German and American Societies of Gastroenterology, they relieve IBS symptoms, such as bloating $[28,29]$. Other studies confirm that probiotics can improve the quality of life and may reduce pain and discomfort in patients with IBS [30]. In addition, abdominal pain is reduced in children using probiotics [31].

\section{Diarrhoea and constipation}

There is an ample evidence of the beneficial effects of probiotics in the treatment of diarrhoea. Administration of probiotics results in a reduced risk of diarrhoea associated with antibiotic use in children [32]. They also reduce the risk of diarrhoea associated with rotavirus infection - in which Lactobacillus rhamnosus is used [33]. In patients with Clostridium difficile-associated diarrhoea and bacterial-negative diarrhoea, probiotics reduced the mean duration of diarrhoea and its frequency and accelerated the recovery [34]. For acute infectious diarrhoea, probiotics also show a therapeutic effect - reducing the average duration of diarrhoea, the number of bowel movements, and the total duration of the discomfort [35]. Probiotics may also reduce the risk of travelers' diarrhoea [36]. They are also effective in the treatment of chronic constipation in children, increasing the frequency of bowel movements, reducing abdominal pain, including during defecation [37]. There is also evidence for the beneficial effects of probiotics in idiopathic constipation in both children and adults [38]. Probiotic supplementation is also indicated for antibiotic therapy - it reduces the risk of post-antibiotic diarrhoea and speeds recovery when it has already occurred [39].

\section{Gastroesophageal reflux}

One of pathomechanisms of gastroesophageal reflux disease (GERD) is the relaxation of the esophageal sphincter muscles by retained gastric contents. It is also believed that one of the causes of this phenomenon is the action of receptors in the gastric mucosa, causing temporary muscle relaxation. Probiotics interact with these receptors, also accelerating the passage of food content to further parts of the gastrointestinal tract [40]. Additionally, probiotics may reduce bacterial overgrowth in small intestine, affecting the immune system and gastrointestinal motility - factors that may also influence the development of reflux [41]. In the majority of studies conducted, administration of probiotics showed positive effects on patients with GER symptoms. The symptoms such as heartburn, abdominal pain, indigestion and nausea were reduced. Although the results seem to be definitely encouraging, both the quality of studies and the heterogeneity of results do not allow draw clear conclusions [42]. Hence, further research in the subject is advisable and also reliable investigation of the abovementioned premises.

\section{Peptic ulcer disease of stomach and duodenum}

One of the most common diseases of the upper gastrointestinal tract is peptic ulcer disease. In the Western world, the incidence is $2.4 \%$, while in Asia it is estimated at $6.1 \%$ [43]. The mechanism of gastric membrane damage is based on the disproportion between protective and destructive factors. Helicobacter pylori 
infection, prolonged intake of nonsteroidal anti-inflammatory drugs, stress and smoking are the most common contributors [44, 45].

In an animal model in which gastric ulcer formation was induced by acetic acid resulting in impaired tissue regeneration due to the rapid emergence of gram-negative bacteria at the ulcer site. On the other hand, the appearance of gram-positive bacteria at the ulcer site improves tissue regeneration. The administration of exogenous Lactobacillus spp. to the rats used in the study ended with a beneficial effect [46]. The importance of probiotics in the context of gastric ulcer treatment is considered in many scientific papers [47]. Strains such as Lactobacillus acidophilus and Bifdobacterium longum have shown to have a good adhesion abilities to the gastric mucosa [48]. They can survive for 3 hours, on average, in an acidic $\mathrm{pH}$ range of 1.5-3.0 [49]. A number of research papers have shown that the use of probiotics for gastric ulcers slows their development and accelerates the healing by synthesis of antimicrobial compounds, blocking the adhesion of pathogenic bacteria, increasing competition for available nutrients, and their immunomodulatory effects that promote mechanisms that lead to gastric mucosal protection. Ultimately, the action of probiotics leads to accelerated regeneration and protection of the gastric wall [47]. Helicobacter pylori infection is one of the most important risk factors for peptic ulcer disease, hence eradication of this bacterium is an important aspect of gastric ulcer prevention [50]. There are works indicating that probiotics may play an auxiliary role in the eradication of Helicobacter pylori [51]. However, the results are inconclusive. There are also reports indicating no positive effect, as compared to placebo [52]. Further studies in this area are necessary to clearly establish the effect of probiotics on $H$. pylori eradication. In conclusion, the use of probiotics in the treatment and prevention of gastric ulcers is extremely promising and the information presented so far puts their efficacy in a positive light, although more research in this direction is needed.

\section{Inflammatory bowel disease, Crohn's disease and ulcerative colitis}

An important role in the pathogenesis of Crohn's disease (CD) is reduced diversity of the gut microbiota. Hence, probiotic-based therapies may be an important adjunct in the treatment of CD [53,54]. Gut dysbiosis is a very important risk factor for Crohn's disease as well as an effect of the disease itself [55]. A disturbed gut microbiota leads to a loss of immune balance, resulting in inflammation in patients genetically susceptible to the development of $\mathrm{CD}$ [56]. Probiotics, which can increase the diversity of the gut microbiota, leading to immune rebalancing, are a good option for treating Crohn's disease. Unfortunately, work on the effect of probiotics in Crohn's disease tends to have small study groups, and the work itself focuses on their efficacy in maintaining remission of CD [54]. Currently, there is too little data to confirm the efficacy of probiotics in the treatment of Crohn's disease, hence probiotics are not considered helpful in therapy [57, 54]. Perhaps future illumination of this topic and larger studies will occur. These are certainly needed to solidify the knowledge of probiotic use in this disease [58]. In ulcerative colitis (UC), probiotics may promote remission, but they cannot maintain it, so it seems that they can be used in disease exacerbations [59]. Nevertheless, a study comparing the use of mesalazine with the use of probiotics indicates that the use of the latter shows no significant difference in maintaining remission [60]. Determination of the definitive role of probiotics in UC therapy requires further research.

\section{Pseudomembranous colitis}

Pseudomembranous colitis leads to severe damage of large intestine in the course of an infection, most commonly caused by the bacterium Clostridium difficile. It is associated with antibiotic therapy leading to disturbance of normal intestinal microflora. Nevertheless, its aetiology may be diverse. Other etiologic factors include heavy metal poisoning, sepsis, or ischemic lesions. Typical symptoms of pseudomembranous colitis are watery diarrhoea, fever, abdominal pain, and leukocytosis [61].

Treatment is based on the withdrawal of antibiotics, if the patient is taking them, and implementation of empiric antibiotic therapy. The choice of antibiotic depends on the severity - metronidazole, vancomycin and fidaxomicin and in some cases rifaximin are used. In case of recurrence and unfavourable results of antibiotics, FMT (foecal microbiota transplant) may be used [62]. Intestinal microbiota transplantation involves the transfer of appropriately processed stool from a healthy donor to the intestine of a patient. The effect is a modulation of the microbiome, resulting in the restoration of a normal intestinal microbiota and resolution of symptoms of pseudomembranous enteritis. Given the clinical efficacy of approximately $90 \%$ [63], this method should be the treatment of choice for this disease, as evidenced by the increasing number of these procedures worldwide [64]. 


\section{Liver diseases}

The use of probiotics in patients with cirrhosis has been shown to significantly reduce the risk of the development of symptomatic hepatic encephalopathy [65]. There is also evidence that probiotics can reduce plasma endotoxin and ammonia levels in patients with minimal hepatic encephalopathy - and thus prevent it from progressing to overt hepatic encephalopathy [66]. A study by Aller et al. suggests that probiotics can reduce aminotransferase and gamma-GTP levels in patients with nonalcoholic steatohepatitis [67]. However, the evidence is too inconclusive at this time to clearly define a role for probiotics in the treatment of this disease [68].

\section{Lactose intolerance}

Probiotics have a potential positive impact in the management of lactose intolerance symptoms; however, further research is required regarding the type of bacteria, their amount, preparation, and understanding the mechanism of action of probiotics in the care of patients with this condition [69].

\section{CONCLUSIONS}

The human microbiota plays a key role in maintaining health. Many studies indicate that the use of probiotics or other methods restoring the balance of microbiota, such as prebiotics, can be a significant factor in improving the prognosis of diseases of the digestive system. At the same time, there is clearly room for further exploration and development of research in this direction. We are just beginning to discover how influence bacteria can have on our lives.

Ethical approval: The conducted research is not related to either human or animal use.

Conflict of interest: Authors declare no conflict of interest.

\section{REFERENCES}

1. Bäckhed F, Ley RE, Sonnenburg JL, Peterson DA, Gordon JI. Host-bacterial mutualism in the human intestine. Science 2005; 307:1915-1920. doi: https://dx.doi.org/10.1126/science.1104816
2. Nash AK, Auchtung TA, Wong MC, et al. The gut mycobiome of the Human Microbiome Project healthy cohort. Microbiome 2017; 5:153. doi: https://dx.doi.org/10.1186/s40168-017-0373-4

3. Scarpellini E, Ianiro G, Attili F, Bassanelli C, De Santis A, Gasbarrini A. The human gut microbiota and virome: Potential therapeutic implications. Dig Liver Dis 2015; 47(12):1007-1012. doi: https://dx.doi.org/10.1016/j.dld.2015.07.008

4. Thursby E, Juge N. Introduction to the human gut microbiota. Biochem J 2017; 474(11): 1823-1836. doi: https://dx.doi.org/10.1042/BCJ20160510

5. Guidelines for the evaluation of probiotics in food report of a joint $\mathrm{FAO} / \mathrm{WHO}$ working group on drafting guidelines for the evaluation of probiotics in food. London Ontario, Canada April 30 and May 1, 2002. https://www.who.int/foodsafety/fs_management/en/probiotic_guidelines. pdf Accessed: April 20, 2021.

6. Gibson G. et al. Dietary prebiotics: current status and new definition. Food Sci Tech Bull Functional Foods 2010; 7:1-19.

7. Lozupone CA, Stombaugh JI, Gordon JI, Jansson JK, Knight R. Diversity, stability and resilience of the human gut microbiota. Nature 2012; 489(7415):220-230. doi: https://dx.doi. org/10.1038/nature11550

8. El Aidy S, Derrien M, Aardema R, et al. Transient inflammatory-like state and microbial dysbiosis are pivotal in establishment of mucosal homeostasis during colonisation of germ-free mice. Benef Microbes 2014; 5:67-77. doi: https://dx.doi. org/10.3920/BM2013.0018

9. Adak A, Khan MR. An insight into gut microbiota and its functionalities. Cell Mol Life Sci 2019; 76(3):473-493. doi: https://dx.doi.org/10.1007/ s00018-018-2943-4

10. Savage DC. Microbial ecology of the gastrointestinal tract. Ann Rev Microbiol 1997; 31:107133. doi: https://dx.doi.org/10.1146/annurev. mi.31.100177.000543

11. Lagier JC, Khelaifia S, Alou M, et al. Culture of previously uncultured members of the human gut microbiota by culturomics. Nat Microbiol 2016; 1:16203. doi: https://dx.doi.org/10.1038/ nmicrobiol.2016.203 
12. Bäckhed F, Ley RE, Sonnenburg JL, Peterson DA, Gordon JI. Host-bacterial mutualism in the human intestine. Science 2005; 307:1915-1920. doi: https://dx.doi.org/10.1126/science.1104816

13. Markowiak P, Śliżewska K. Effects of probiotics, prebiotics, and synbiotics on human health. Nutrients 2017; 9:1021. doi: https://dx.doi. org/10.3390/nu9091021

14. Hess JM, Jonnalagadda SS, Slavin JL. Dairy Foods: Current evidence of their effects on bone, cardiometabolic, cognitive, and digestive health. Compr Rev Food Sci Food Safe 2016; 15:251-268. doi: https://dx.doi.org/10.1111/1541-4337.12183

15. Bron PA, Kleerebezem M, Brummer RJ, et al. Can probiotics modulate human disease by impacting intestinal barrier function? Br J Nutr 2017; 117(1):93-107. doi: https://dx.doi.org/10.1017/ S0007114516004037

16. Souvik T, John D, Ankita G. A review on probiotic dairy products and digestive health. J Pharmacogn Phytochem 2019; 8(3):368-372.

17. Cleusix V, Lacroix C, Vollenweider S, Duboux $\mathrm{M}$, Le Blay G. Inhibitory activity spectrum of reuterin produced by Lactobacillus reuteri against intestinal bacteria. BMC Microbiol 2007; 7:101. doi: https://dx.doi.org/10.1186/1471-2180-7-101

18. Corr SC, Li Y, Riedel CU, O’Toole PW, Hill C, Gahan CG. Bacteriocin production as a mechanism for the antiinfective activity of Lactobacillus salivarius UCC118. Proc Natl Acad Sci USA 2007; 104(18):7617-7621. doi: https://dx.doi. org/10.1073/pnas.0700440104

19. Rescigno M, Di Sabatino A. Dendritic cells in intestinal homeostasis and disease. J Clin Invest 2009; 119(9):2441-2450. doi: https://dx.doi. org/10.1172/JCI39134

20. Corthésy B. Multi-faceted functions of secretory IgA at mucosal surfaces. Front Immunol 2013; 4:185. doi: https://dx.doi.org/10.3389/fimmu.2013.00185

21. Everard A, Geurts L, Caesar R, et al. Intestinal epithelial MyD88 is a sensor switching host metabolism towards obesity according to nutritional status. Nat Commun 2014; 5:5648. doi: https:// dx.doi.org/10.1038/ncomms6648
22. Cash HL, Whitham CV, Behrendt CL, Hooper LV. Symbiotic bacteria direct expression of an intestinal bactericidal lectin. Science 2006; 313:1126-1130. doi: https://dx.doi.org/10.1126/ science.1127119

23. Marlicz W, Yung DE, Skonieczna-Żydecka K, et al. From clinical uncertainties to precision medicine: the emerging role of the gut barrier and $\mathrm{mi}-$ crobiome in small bowel functional diseases. Expert Rev Gastroenterol Hepatol 2017; 11(10):961978. doi: https://dx.doi.org/10.1080/17474124.20 17.1343664

24. Bäckhed F, Fraser CM, Ringel Y, et al. Defining a healthy human gut microbiome: current concepts, future directions, and clinical applications. Cell Host Microbe 2012; 12(5):611-622. doi: https://dx.doi.org/10.1016/j.chom.2012.10.012

25. Wang L, Alammar N, Singh R, et al. Gut microbial dysbiosis in the irritable bowel syndrome: A systematic review and meta-analysis of case-control sudies. J Acad Nutr Diet 2020; 120(4):565-586. doi: https://dx.doi.org/10.1016/j. jand.2019.05.015

26. Nishida A, Inoue R, Inatomi O, Bamba S, Naito Y, Andoh A. Gut microbiota in the pathogenesis of inflammatory bowel disease. Clin J Gastroenterol 2018; 11(1):1-10. doi: https://dx.doi.org/10.1007/ s12328-017-0813-5

27. Syer SD, Blackler RW, Martin R, et al. NSAID enteropathy and bacteria: a complicated relationship. J Gastroenterol 2015; 50(4):387-393. doi: https://dx.doi.org/10.1007/s00535-014-1032-1

28. Layer P, Andresen V, Pehl C, et al. S3-Leitlinie Reizdarmsyndrom: Definition, Pathophysiologie, Diagnostik und Therapie. Gemeinsame Leitlinie der Deutschen Gesellschaft für Verdauungsund Stoffwechselkrankheiten (DGVS) und der Deutschen Gesellschaft für Neurogastroenterologie und Motilität (DGNM)1 [Irritable bowel syndrome: German consensus guidelines on definition, pathophysiology and management]. Z Gastroenterol 2011; 49(2):237-293. [in German] doi: https://dx.doi.org/10.1055/s-0029-1245976

29. Ford AC, Moayyedi P, Lacy BE, et al. American College of Gastroenterology monograph on the management of irritable bowel syndrome and chronic idiopathic constipation. Am J Gastro- 
enterol 2014; 109:S2-S26. doi: https://dx.doi. org/10.1038/ajg.2014.187

30. Zhang Y, Li L, Guo C, et al. Effects of probiotic type, dose and treatment duration on irritable bowel syndrome diagnosed by Rome III criteria: a meta-analysis. BMC Gastroenterol 2016; 16:62. https://dx.doi.org/10.1186/s12876-016-0470-z

31. Korterink JJ, Ockeloen L, Benninga MA, Tabbers MM, Hilbink M, Deckers-Kocken JM. Probiotics for childhood functional gastrointestinal disorders: a systematic review and meta-analysis. Acta Paediatr 2014; 103(4):365-372. doi: https:// dx.doi.org/10.1111/apa.12513

32. Guo Q, Goldenberg JZ, Humphrey C, El Dib R, Johnston BC. Probiotics for the prevention of pediatric antibiotic-associated diarrhea. Cochrane Database Syst Rev 2019; 4(4):CD004827. doi: https:// dx.doi.org/10.1002/14651858.CD004827.pub5

33. Szajewska H, Skórka A, Ruszczyński M, Gieruszczak-Białek D. Meta-analysis: Lactobacillus GG for treating acute gastroenteritis in children - updated analysis of randomised controlled trials. Aliment Pharmacol Ther 2013; 38(5):467476. doi: https://dx.doi.org/10.1111/apt.12403

34. Shan LS, Hou P, Wang ZJ, et al. Prevention and treatment of diarrhoea with Saccharomyces boulardii in children with acute lower respiratory tract infections. Benef Microbes 2013; 4:329-334. doi: https://dx.doi.org/10.3920/BM2013.0008

35. Allen SJ, Martinez EG, Gregorio GV, Dans LF. Probiotics for treating acute infectious diarrhoea. Cochrane Database Syst Rev 2010; 2010(11):CD003048. doi: https://dx.doi. org/10.1002/14651858.CD003048.pub3

36. McFarland LV. Meta-analysis of probiotics for the prevention of traveler's diarrhea. Travel Med Infect Dis 2007; 5:97-105. doi: https://dx.doi. org/10.1016/j.tmaid.2005.10.003

37. Guerra PV, Lima LN, Souza TC, et al. Pediatric functional constipation treatment with $\mathrm{Bi}$ fidobacterium-containing yogurt: a crossover, double-blind, controlled trial. World J Gastroenterol 2011; 17(34):3916-3921. doi: https://dx.doi. org/10.3748/wjg.v17.i34.3916

38. Ford AC, Quigley EM, Lacy BE, et al. Efficacy of prebiotics, probiotics, and synbiotics in irritable bowel syndrome and chronic idiopathic constipation: systematic review and meta-analysis. Am J Gastroenterol 2014; 109(10):1547-1562. doi: https://dx.doi.org/10.1038/ajg.2014.202

39. Hempel S, Newberry SJ, Maher AR, et al. Probiotics for the prevention and treatment of antibiotic-associated diarrhea: a systematic review and meta-analysis. JAMA 2012; 307:1959-1969. doi: https://dx.doi.org/10.1001/jama.2012.3507

40. Indrio F, Riezzo G, Raimondi F, et al. Lactobacillus reuteri accelerates gastric emptying and improves regurgitation in infants. Eur J Clin Invest 2011; 41:417-422. doi: https://dx.doi.org/10.1111/ j.1365-2362.2010.02425.x

41. Quigley EM, Quera R. Small intestinal bacterial overgrowth: roles of antibiotics, prebiotics, and probiotics. Gastroenterology 2006; 130(2 Suppl. 1):S78-S90. doi: https://dx.doi.org/10.1053/j.gastro.2005.11.046

42. Cheng J, Ouwehand AC. Gastroesophageal reflux disease and probiotics: A systematic review. Nutrients 2020; 12(1):132. doi: https://dx.doi. org/10.3390/nu12010132

43. Sung JJ, Kuipers EJ, El-Serag HB. Systematic review: the global incidence and prevalence of peptic ulcer disease. Aliment Pharmacol Ther 2009; 29:938-946. doi: https://dx.doi.org/10.1111/ j.1365-2036.2009.03960.x

44. Hirayama F, Takagi S, Kusuhara H, Iwao E, Yokoyama Y, Ikeda Y. Induction of gastric ulcer and intestinal metaplasia in Mongolian gerbils infected with Helicobacter pylori. J Gastroenterol 1996; 31(5):755-757. doi: https://dx.doi.org/10.1007/ BF02347631

45. Wang GZ, Huang GP, Yin GL, Zhou G, Guo CJ, et al. Aspirin can elicit the recurrence of gastric ulcer induced with acetic acid in rats. Cell Physiol Biochem 2007; 20(1-4):205-212. doi: https:// dx.doi.org/10.1159/000104167

46. Elliott SN, Buret A, McKnight W, Miller MJ, Wallace JL. Bacteria rapidly colonize and modulate healing of gastric ulcers in rats. Am J Physiol Cell Physiol 1998; 275(3):G425-G432. doi: https:// dx.doi.org/10.1152/ajpgi.1998.275.3.G425

47. Khoder G, Al-Menhali AA, Al-Yassir F, Karam SM. Potential role of probiotics in the man- 
agement of gastric ulcer. Exp Ther Med 2016; 12(1):3-17. doi: https://dx.doi.org/10.3892/ etm. 2016.3293

48. Clark PA, Cotton LN, Martin JH. Selection of bifidobacteria for use as dietary adjuncts in cultured dairy foods. II. Tolerance to simulated $\mathrm{pH}$ of human stomachs. Cult Dairy Prod J 1993; 28(4):11-14.

49. Lankaputhra W, Shah NP. Survival of Lactobacillus acidophilus and Bifidobacterium spp. in the presence of acid and bile salts. Cult Dairy Prod J 1995; 30:2-7.

50. Asaka M, Kato M, Kudo M, Meguro T, Kimura T, Miyazaki T, Inoue K. The role of Helicobacter pylori in peptic ulcer disease. Gastroenterol Jpn 1993; 28 (Suppl. 5):163-167. doi: https://dx.doi. org/10.1007/BF02989228

51. Zheng X, Lyu L, Mei Z. Lactobacillus-containing probiotic supplementation increases Helicobacter pylori eradication rate: evidence from a metaanalysis. Rev Esp Enferm Dig 2013; 105(8):445453. doi: https://dx.doi.org/10.4321/s113001082013000800002

52. Lu C, Sang J, He H, Wan X, Lin Y, Li L et al. Probiotic supplementation does not improve eradication rate of Helicobacter pylori infection compared to placebo based on standard therapy: a meta-analysis. Sci Rep 2016; 6:23522. doi: https://dx.doi.org/10.1038/srep23522

53. Sartor RB, Wu GD. Roles for intestinal bacteria, viruses, and fungi in pathogenesis of inflammatory bowel diseases and therapeutic approaches. Gastroenterology 2017; 152(2):327-339.e4. doi: https://dx.doi.org/10.1053/j.gastro.2016.10.012

54. Khanna S, Raffals LE. The microbiome in Crohn's disease: Role in pathogenesis and role of microbiome replacement therapies. Gastroenterol Clin North Am 2017; 46(3):481-492. doi: https:// dx.doi.org/10.1016/j.gtc.2017.05.004

55. Kostic AD, Xavier RJ, Gevers D. The microbiome in inflammatory bowel disease: current status and the future ahead. Gastroenterology 2014; 146(6):1489-1499. doi: https://dx.doi. org/10.1053/j.gastro.2014.02.009

56. Colombel JF. Decade in review-IBD: IBD-genes, bacteria and new therapeutic strategies. Nat Rev
Gastroenterol Hepatol 2014; 11(11):652-654. doi: https://dx.doi.org/10.1038/nrgastro.2014.170

57. Dong J, Teng G, Wei T, Gao W, Wang H. Methodological quality assessment of meta-analyses and systematic reviews of probiotics in inflammatory bowel disease and pouchitis. PloS one 2016; 11(12):e0168785. doi: https://dx.doi.org/10.1371/ journal.pone.0168785

58. Limketkai BN, Akobeng AK, Gordon M, Adepoju AA. Probiotics for induction of remission in Crohn's disease. Cochrane Database Syst Rev 2020; 7(7):CD006634. doi: https://dx.doi. org/10.1002/14651858.CD006634.pub3

59. Shen J, Zuo ZX, Mao AP. Effect of probiotics on inducing remission and maintaining therapy in ulcerative colitis, Crohn's disease, and pouchitis: meta-analysis of randomized controlled trials. Inflamm Bowel Dis 2014; 20(1):21-35. doi: https:// dx.doi.org/10.1097/01.MIB.0000437495.30052. be

60. Naidoo K, Gordon M, Fagbemi AO, Thomas AG, Akobeng AK. Probiotics for maintenance of remission in ulcerative colitis. Cochrane Database Syst Rev 2011; 12:CD007443. doi: https://dx.doi. org/10.1002/14651858.CD007443.pub2

61. Surawicz CM, McFarland LV. Pseudomembranous colitis: causes and cures. Digestion 1999; 60(2):91-100. doi: https://dx.doi. org $/ 10.1159 / 000007633$

62. Dinleyici M, Vandenplas Y. Clostridium difficile colitis prevention and treatment. Adv Exp Med Biol 2019; 1125:139-146. doi: https://dx.doi. org/10.1007/5584_2018_322

63. Kassam Z, Lee CH, Yuan Y, Hunt RH. Fecal microbiota transplantation for Clostridium difficile infection: systematic review and meta-analysis. Am J Gastroenterol 2013; 108(4):500-508. doi: https://dx.doi.org/10.1038/ajg.2013.59

64. Stallmach A, Steube A, Grunert P, Hartmann M, Biehl LM, Vehreschild M. Fecal microbiota transfer. Dtsch Arztebl Int 2020; 117(3):31-38. doi: https://dx.doi.org/10.3238/arztebl.2020.0031

65. Xu J, Ma R, Chen LF, Zhao LJ, Chen K, Zhang RB. Effects of probiotic therapy on hepatic encephalopathy in patients with liver cirrhosis: an up- 
dated meta-analysis of six randomized controlled trials. HBPD Int 2014; 13(4):354-360. doi: https:// dx.doi.org/10.1016/s1499-3872(14)60280-0

66. Cao Q, Yu CB, Yang SG, Cao HC, Chen P, Deng M, Li LJ. Effect of probiotic treatment on cirrhotic patients with minimal hepatic encephalopathy: A meta-analysis. HBPD Int 2018: 17(1):9-16. doi: https://dx.doi.org/10.1016/j.hbpd.2018.01.005

67. Aller R, De Luis DA, Izaola O, Conde R, Gonzalez Sagrado M, Primo D et al. Effect of a probiotic on liver aminotransferases in nonalcoholic fatty liver disease patients: a double blind randomized clinical trial. Eur Rev Med Pharmacol Sci 2011; 15(9):1090-1095.
68. Buss C, Valle-Tovo C, Miozzo S, Alves de Mattos A. Probiotics and synbiotics may improve liver aminotransferases levels in non-alcoholic fatty liver disease patients. Ann Hepatol 2014; 13(5):482-488.

69. Oak SJ, Jha R. The effects of probiotics in lactose intolerance: A systematic review. Crit Rev Food Sci Nutr 2019; 59(11):1675-1683. doi: https:// dx.doi.org/10.1080/10408398.2018.1425977 